\title{
Infection of Ixodes ricinus (Acari: Ixodidae) by Borrelia burgdorferi sensu lato in North Africa
}

\author{
ELYES ZHIOUA, ${ }^{1}$ ALI BOUATTOUR,${ }^{2}$ CHANG MIN HU, ${ }^{3}$ MOHAMED GHARBI, ${ }^{2}$ \\ ANDRE AESCHLIMAN,${ }^{3}$ HOWARD S. GINSBERG ${ }^{4}{ }_{\text {AND LISE GERN }}^{3}$
}

\begin{abstract}
J. Med. Entomol. 36(2): 216-218 (1999)
ABSTRACT Free-living adult Ixodes ricinus L. were collected in Amdoun, situated in the Kroumiry mountains in northwestern Tunisia (North Africa). Using direct fluorescence antibody assay, the infection rate of field-collected I. ricinus by Borrelia burgdorferi sensu lato was $30.5 \%(n=72)$. No difference in infection rate was observed between male and female ticks. Spirochetes that had been isolated from I. ricinus from Ain Drahim (Kroumiry Mountains) in 1988 were identified as Borrelia lusitaniae (formerly genospecies PotiB2). This is the first identification of a genospecies of Borrelia burgdorferi sensu lato from the continent of Africa.
\end{abstract}

KEY WORDS Ixodes ricinus, Borrelia burgdorferi, Borrelia lusitaniae, Tunisia

IN EuRope, Ixodes ricinus L. is the principal vector of Borrelia burgdorferi, the etiologic agent of Lyme borreliosis (Aeschlimann et al. 1986). Borrelia burgdorferi sensu lato is now known to include at least 5 genospecies associated with $I$. ricinus: Borrelia burgdorferi sensu stricto, Borrelia garinii, Borrelia afzelii, Borrelia valaisiana (formerly genospecies VS116), and Borrelia lusitaniae (formerly genospecies PotiB2) (Baranton et al. 1992; Canica et al. 1993; Postic et al. 1994, 1997; Le Flèche et al. 1997; Wang et al. 1997). The geographical distribution of $I$. ricinus covers southern Scandinavia, the British Isles, Central Europe, France, Spain, Portugal, Italy, the Balkans, East Europe, northern Iran, and North Africa (Perez and Rodhain 1977, Stanek et al. 1988). Infection of I. ricinus by B. burgdorferi sensu lato has been reported from many European countries. In Africa, however, primarily serological and clinical results have been reported (Stanek et al. 1986, Ginsburg et al. 1991, Zahaf et al. 1994, Mhalu and Matre 1996), and few entomological studies have been performed (Zhioua et al. 1989). The objectives of this study were to determine the infection rate of $I$. ricinus by B. burgdorferi sensu lato at a sample site in Northern Africa (Tunisia), and to identify the genospecies of Borrelia isolated from I. ricinus from Tunisia.

\section{Materials and Methods}

Study Site. In Tunisia, I. ricinus is localized in the northwest, mainly in the mountains of Kroumiry (At-

\footnotetext{
${ }^{1}$ Center for Vector-Borne Disease, Woodward Hall, University of Rhode Island, Kingston, RI 02881.

${ }^{2}$ Institute Pasteur of Tunis, Department of Medical Entomology, 13 Place Pasteur, 1002 Tunis, Tunisia.

${ }^{3}$ Institute of Zoology, Emile Argand 11, University of Neuchâtel, Neuchâtel, Switzerland.

${ }^{4}$ USGS Patuxent Wildlife Research Center, Woodward Hall-PLS, University of Rhode Island, Kingston, RI 02881.
}

las mountains), where it is abundant in oak forests (Zhioua et al. 1989, Bouattour and Darghouth 1996). These forests have rich undergrowth and harbor small mammals, deer, and wild boar (Gharaibeh 1997). The activity peak of adult $I$. ricinus in this area is in February-March (Senevet and Rossi, 1924, Sergent and Poncet 1937, Yousfi-Monod and Aeschlimann 1986), so we sampled ticks in March 1996. Unfed adult ticks were collected by flagging or by direct collection from the grass in the region of Amdoun (Kroumiry).

Spirochete Detection. Adults were surface-sterilized and dissected to remove the gut. Midguts were chilled, placed on glass slides, and examined for the presence of spirochetes using direct fluorescent antibody assay (DFA) (Zhioua et al. 1994). Antigens were dried for at least $2 \mathrm{~h}$ at $34^{\circ} \mathrm{C}$ and subsequently fixed with acetone for $10 \mathrm{~min}$. Preparations were stained directly with high-titered fluorescein isothiocyanate conjugated anti-B. burgdorferi goat antibody (KPL, Gaithersburg, MD).

In 1988, spirochetes were isolated from field-collected I. ricinus from the region of Ain Drahim (Kroumiry, Tunisia) (Zhioua et al. 1989). Unfortunately, identification of these spirochetes was not possible in 1988 because the cultures were contaminated (Zhioua et al. 1989), and the isolates were stored at $-70^{\circ} \mathrm{C}$. Technical advances now allow characterization of these isolates. Borrelia isolates were identified in 1996 by $r r f(5 \mathrm{~S})$ - rrf (23S) spacer restriction fragment-length polymorphism (RFLP) analysis as described by Postic et al. (1994).

\section{Results and Discussion}

In total, 72 adult $I$. ricinus (41 females, 31 males) collected from Amdoun in 1996 were examined for the presence of B. burgdorferi sensu lato by DFA. The infection rate was $30.5 \%(22 / 72)$. No significant dif- 


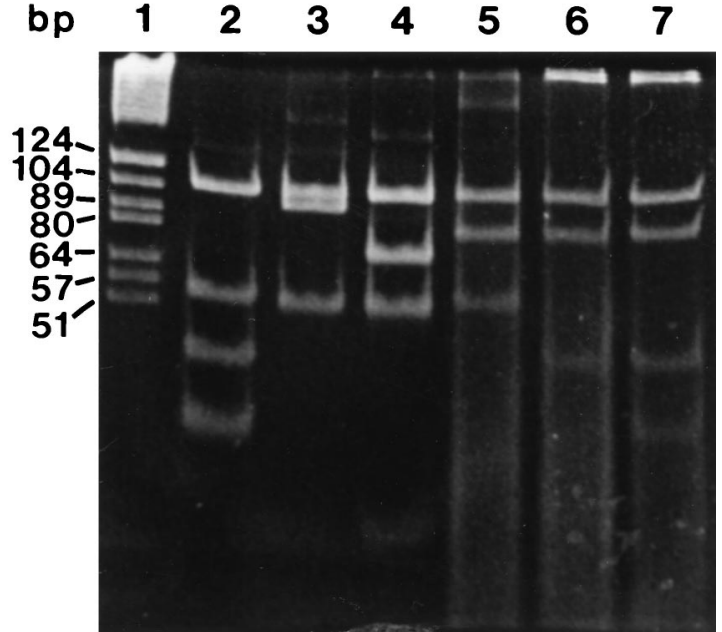

Fig. 1. MseI restriction patterns of B. burgdorferi sensu lato. Lane 1, DNA size standards; lane 2, B. burgdorferi sensu stricto; lane 3, B. garinii; lane 4, B. afzelii; lane 5, B. lusitaniae; lanes 6 and 7, Tunisian isolates.

ference was observed between the infection rates of females $(36.6 \%, n=41)$ and males $(22.6 \%, n=31)\left(\chi^{2}\right.$ $=1.63, \mathrm{df}=1, P=0.2$ ).

Identification of 2 strains of spirochetes isolated from Tunisia in 1988 showed 1 genospecies, B. lusitaniae (Fig. 1). Borrelia burgdorferi sensu stricto, $B$. garinii, B. afzelii, and B. valaisiana were not observed.

Here, we report the presence of $B$. burgdorferi sensu lato in I. ricinus on the African continent. On a subtropical island in the Atlantic, northwest of continental Africa, the infection rate of I. ricinus by B. burgdorferi was 1.3\% (Matuschka et al. 1994). The 30.5\% infection rate we observed in Tunisia is within the range reported from European countries-13.8\% in Spain (Mareuez and Constan 1990), 9.6\% in Belgium (Martin et al. 1990), 5-50\% in Switzerland (Aeschlimann et al. 1986, Gern et al. 1992), 20\% in the Netherlands (Rijpkema et al. 1994), 18\% in Germany (Matuschka et al. 1992), 13\% in Slovenia (Strle et al. 1995), $45 \%$ in Croatia (Rijpkema et al. 1996), and $12.4 \%$ in France (Zhioua et al. 1996). Additional studies are needed to determine the infection rates of immatures and to identify the reservoir hosts of B. burgdorferi sensu lato in Tunisia.

Borrelia burgdorferi sensu stricto is the only pathogenic genospecies currently known to be present in the United States (Postic et al. 1994). In Eurasia, B. afzelii and B. garinii are widely distributed (Fukunaga and Hamase 1995, Postic et al. 1997). In Europe, 3 genospecies associated with Lyme borreliosis have been recognized to date- $B$. burgdorferi sensu stricto, B. garinii, and B. afzelii. These genospecies have been isolated from patients, rodents, birds, and I. ricinus from various areas in Europe (Humair et al. 1995, Olsen et al. 1995, Picken et al. 1996, Zhioua et al. 1996, Postic et al. 1997). Two additional genospecies have been observed in I. ricinus and identified as B. valaisiana and B. lusitaniae (formerly the genospecies
VS116 and PotiB2, respectively) (Postic et al. 1994, 1997; Péter et al. 1995; Rijpkema et al. 1995; Le Flèche et al. 1997; Wang et al. 1997). To date, only a few isolates have been identified as B. lusitaniae; 3 from Portugal, 2 from Moldavia, 1 from Ukraine, 1 from Czech Republic (Postic et al. 1994, 1997), and now 1 from North Africa. The roles of B. lusitaniae and $B$. valaisiana in the etiology of Lyme borreliosis remain to be clarified.

In western, central, and northern Europe, I. ricinus is commonly infected with various Borrelia genospecies, but rarely with $B$. lusitaniae, which appears to be limited to the southern part of the northern Hemisphere. Additional isolates from I. ricinus are necessary to describe the heterogeneity of spirochetes and the distribution of the various genospecies in southern Europe and North Africa. In sub-Saharan Africa, the existence of $B$. burgdorferi sensu lato remains unclear, but seems to be improbable because of the absence of ticks of the I. ricinus species complex (Mason et al. 1994, Marjolet et al. 1995).

\section{Acknowledgments}

The authors thank K. Dellagi (Director, Pasteur Institute of Tunis) for his constant support, including logistics and laboratory facilities. We also thank R. A. LeBrun, P. Logan, D. Dennis, and A. Spielman for constructive comments on early drafts of the manuscript. Raquel Martinez and Paul Johnson provided technical assistance. This work benefited from support by the Swiss National Science Foundation (Grant Nos. 3.975.87 and 32-29964.90), the U.S. National Biological Service, and the Department of Plant Sciences. This is Contribution No. 3446 of the College of Resource Development, University of Rhode Island.

\section{References Cited}

Aeschlimann, A., E. Chamot, F. Gigon, J.-P. Jeanneret, D. Kesseler, and C. Walter. 1986. Borrelia burgdorferi in Switzerland. Zentralbl. Bakteriol. Microbiol. Hyg. Ser. A 263: $450-458$.

Baranton, G., D. Postic, I. Saint-Girons, P. Boerlin, J. C. Piffaretti, M. Assous, and P.A.D. Grimont. 1992. Delineation of Borrelia burgdorferi sensu stricto, Borrelia garinii sp. nov., and Group VS461 associated with Lyme borreliosis. Int. J. Syst. Bacteriol. 42: 378-383.

Bouattour, A., and M. A. Darghouth. 1996. First report of Babesia divergens in Tunisia. Vet. Parasitol. 63: 161-165.

Canica, M. M., F. Nato, L. du Merle, J. C. Mazie, G. Baranton, and D. Postic. 1993. Monoclonal antibodies for the identification of Borrelia afzelii sp. nov., associated with late cutaneous manifestations of Lyme borreliosis. Scand. J. Infect. Dis. 25: 441-448.

Fukunaga, M., and A. Hamase. 1995. Outer surface protein $\mathrm{C}$ gene sequence analysis of Borrelia burgdorferi sensu lato isolates from Japan. J. Clin. Microbiol. 33: 2415-2420.

Gern, L., W. Burgdorfer, A. Aeschlimann, and H. E. Krampitz. 1992. The ecology of Lyme borreliosis in Europe, pp. 59-69. In K. Weber and W. Burgdorfer [eds.], Aspects of Lyme borreliosis. Spring, Berlin.

Gharaibeh, B. M. 1997. Systematics, distribution, and zoogeography of mammals of Tunisia. Ph.D. dissertation, Texas Tech University, Lubbock, TX. 
Ginsburg, Ch., C. Saint-Val, J. F. Eizenbaum, and J. D. Degos. 1991. Maladie de Lyme africaine. Pres. Med. 20: 21612162.

Humair, P. F., O. Péter, R. Wallich, and L. Gern. 1995. Strain variation of Lyme disease spirochetes isolated from Ixodes ricinus ticks and rodents collected in two endemic areas in Switzerland. J. Med. Entomol. 32: 433-438.

Le Flèche, A., D. Postic, K. Girardet, O. Péter, and G. Baranton. 1997. Characterization of Borrelia lusitaniae sp. nov. by $16 \mathrm{~S}$ ribosomal DNA sequence analysis. Int. J. Syst. Bacteriol. 47: 921-925.

Mareuez, F. J., and M. C. Constan. 1990. Infection d'Ixodes ricinus (L. 1758) et Haemaphysalis punctata Canestrini et Franzo, 1877 (Acarina, Ixodidae) par Borrelia burgdorferi dans le nord de la péninsule ibérique (Pays Basque Espagnol et Navarre). Bull. Soc. Fr. Parasitol. 8: 323-330.

Marjolet, M., B. Gueglio, and M. Traoure. 1995. Does Lyme disease (or an analogous disease) exist in Mali, West Africa? Trans. R. Soc. Trop. Med. Hyg. 89: 387.

Martin, Ph., G. Bigaignon, A. Thirion, and A. Fain. 1990. Fréquence de Borrelia burgdorferi (maladie de Lyme) et répartition de son vecteur Ixodes ricinus (Acari: Ixodidae) dans le district de Mosan de Belgique. Bull. Soc. Fr. Parasitol. 8: 331-338.

Mason, P. R., P. J. Kelly, I. Nilson, and T. Wadstrom. 1994. Apparent absence of Lyme borreliosis in Zimbabwe. Trans. R. Soc. Trop. Med. Hyg. 88: 412.

Matuschka, F. R., P. Fisher, M. Heiler, S. Blümcke, and A. Spielman. 1992. Stage-associated risk of transmission of the Lyme disease spirochete by European Ixodes ticks. Parasitol. Res. 78: 695-698.

Matuschka, F. K., H. Eiffer, A. Ohlenbusch, D. Richter, E. Schein, and A. Spielmann. 1994. Transmission of the Lyme disease on a subtropical island. Trop. Med. Parasitol. 45: $39-44$.

Mhalu, F. S., and R. Matre. 1996. Serological evidence of Lyme borreliosis in Africa: results from studies in Dar es Salem, Tanzania. East. Afr. Med. J. 73: 583-585.

Olsen, B., T.G.T. Jaenson, and S. Bergström. 1995. Prevalence of Borrelia burgdorferi sensu lato-infected ticks on migrating birds. Appl. Environ. Microbiol. 61: 3082-3087.

Perez, C., and F. Rodhain. 1977. Biologie d'Ixodes ricinus L., 1758. I. Ecologie, cycle évolutif. Bull. Soc. Pathol. Exot. 70: 187-201.

Péter, O., A. G. Bretz, and D. Bee. 1995. Occurrence of different genospecies of Borrelia burgdorferi sensu lato in ixodid ticks of Valais, Switzerland. Eur. J. Epidemiol. 11: 463-467.

Picken, R. N., Y. Cheng, F. Strle, J. Cimperman, V. Maraspin, S. Lotric-Furlan, E. Ruzic-Sabljic, D. Han, J. A. Nelson, M. M. Picken, and G. M. Trenholme. 1996. Molecular characterization of Borrelia burgdorferi sensu lato from Slovenia revealing significant differences between tick and human isolates. Eur. J. Clin. Microbiol. Infect. Dis. 15: 313-323.

Postic, D., M. V. Assous, P.A.D. Grimont, and G. Baranton. 1994. Diversity of Borrelia burgdorferi sensu lato evidenced by restriction fragment length polymorphism of $r r f(5 S)-r r f(23 S)$ intergenic spacer amplicons. Int. J. Sys. Bacteriol. 44: 743-752.

Postic, D., E. Korenberg, N. Gorelova, Y. V. Kovalevski, E. Bellenger, and G. Baranton. 1997. Borrelia burgdorferi sensu lato in Russia and neighbouring countries: high incidence of mixed isolates. Res. Microbiol. 148: 691-702.
Rijpkema, S.G.T., J. Nieuwenhuiis, F.F.J. Franssen, and F. J. Jongejan. 1994. Infection rates of Borrelia burgdorferi in different instars of Ixodes ricinus from the Duch North Sea Island of Ameland. Exp. Appl. Acarol. 18: 531-542.

Rijpkema, S.G.T., M.J.C.H. Molkenboer, L. M. Schouls, F. J. Jongean, and J.F.P. Schellekens. 1995. Simultaneous detection and genotypic of three genomic groups of Borrelia burgdorferi sensu lato in Dutch Ixodes ricinus ticks by characterization of the amplified intergenic spacer region between $5 \mathrm{~S}$ and $23 \mathrm{~S}$ rRNA genes. J. Clin. Microbiol. 33: 3091-3095.

Rijpkema, S.G.T., D. Golubic, M. Molkenboer, N. Verbeek-De Kruif, and J. Schellekens. 1996. Identification of four genomic groups of Borrelia burgdorferi sensu lato in Ixodes ricinus ticks collected in a Lyme borreliosis endemic region of northern Croatia. Exp. Appl. Acarol. 20: 23-30.

Senevet, G., and P. Rossi. 1924. Contribution à l'étude des Ixodidés (XII Note). Etude saisonnière des ixodidés dans la région de Bouira (Algérie). Arch. Inst. Pasteur Alger. 2: 223-232.

Sergent, E., and A. Poncet. 1937. Tableau de la répartition saisonnière des tiques les plus répandues en Algérie. Arch. Inst. Pasteur Alger. 37: 220-224.

Stanek, G., A. Hirschl, H. Stemberger, G. Wewalka, and G. Wiedermann. 1986. Does Lyme borreliosis occur in tropical and subtropical areas? Zentralbl. Bakteriol. Microbiol. Hyg. Ser. A 263: 491-495.

Stanek, G., M. Pletschette, H. Flamm, A. M. Hirschl, E. Aberer, W. Kristoferitsch, and E. Schmutzhard. 1988. European Lyme borreliosis. Ann. N.Y. Acad. Sci. 539: 274-282.

Strle, F., Y. Cheng, M. Picken, J. K. Bouseman, and R. N. Picken. 1995. Infection rates of Ixodes ricinus ticks with Borrelia afzelii, Borrelia garinii, and Borrelia burgdorferi sensu stricto in Slovenia. Eur. J. Clin. Microbiol. Infect. Dis. 14: 994-1001.

Wang, G., A. P. van Dam, A. Le Flèche, D. Postic, G. Baranton, R. de Boer, L. Spanjaard, and J. Dankert. 1997. Genetic and phenotypic analysis of Borrelia valaisiana sp. nov. (Borrelia genomic groups VS116 and M19). Int. J. Syst. Microbiol. 47: 926-932.

Yousfi-Monod, R., and A. Aeschlimann. 1986. Recherche sur les tiques (Acarina, Ixodidae) parasites des bovidés dans l'ouest algérien. I- Inventaire systématique et dynamique saisonnière. Ann. Parasitol. Hum. Comp. 61: 341-358.

Zahaf, A., S. Bouassida, S. Boudaya, and H. Turki. 1994. La maladie de Lyme à Sfax. Ann. Dermatol. Venereol. 121: 177-179.

Zhioua, E., L. Gern, and A. Aeschlimann. 1989. Isolement d'un spirochète à partir d'Ixodes ricinus de Tunisie. Bull. Soc. Fr. Parasitol. 7: 107-110.

Zhioua, E., A. Aeschlimann, and L. Gern. 1994. Infection of field-collected Ixodes ricinus (Acari: Ixodidae) larvae with Borrelia burgdorferi in Switzerland. J. Med. Entomol. 31: 763-766.

Zhioua, E., D. Postic, F. Rodhain, and C. Perez-Eid. 1996. Infection of Ixodes ricinus (Acari: Ixodidae) by Borrelia burgdorferi in Ile de France. J. Med. Entomol. 34: 694697. Recei
1998.
Received for publication 27 March 1998; accepted 13 October 